\title{
INFRASTRUCTURE OPERATION RELIABILITY IN BUILT-UP AREAS
}

\begin{abstract}
Reliability and safety of energy, drinking water deliveries and draining wastewater from built- up areas in cities and villages have many proportions and technical-operational conditions. Among basic requirements of the use of all types of residential or manufacturing objects in the $21^{\text {st }}$ century is reliable delivery of drinking water, draining and cleaning of urban and industrial sewage. Disturbance or putting out of service of this type of infrastructure has always a domino effect. Gradually growing reliance of user base of all types of drinking water consumers leads especially in the section of the public or private infrastructure to restriction or complete stoppage of their operation. The following article defines in basic range the ways and means how to lower the danger that an emergency situation in operational systems of drinking water will be unmanageable and how to prevent natural or anthropogenic threats at the particular type of technical infrastructure.
\end{abstract}

Keywords: Water, drinking water, water main, hydraulic surrounding, infrastructure of an area, risk, risk analysis.

\section{Introduction}

Operational ability of infrastructure in cities and villages is today dependent from $100 \%$ on drinking water and energies supplies. Technical-operational problems appear even after a short term interruption of the supplies to media mentioned above. For example, a short term interruption of direct drinking water supplies to medical and accommodation services causes collapse in their working. Similar situation arises in the food processing plants and sanitary institutions of other infrastructure and in residential areas.

Should technical-operational facilities of water systems carry out their required function, they have to have sufficient hydraulic and operational preconditions. The input preconditions of hydraulic efficiency of water systems develop as soon as the waterworks are projected by the calculation or mathematical modelling of water mains and can be considered as sufficient. But real operational conditions change and in the terms of time get worse. The following article in its basic form implies under which conditions and in which situations this happens.

\section{Operational and hydraulic preconditions for waterworks systems working}

Water systems of crude and especially drinking water are significantly different compared to other types of technical infrastructure. They do not work only with media but with one of the most important kind of food, without which the human life, food processing and operating minimally all kinds of the city and village sanitary institutions are not possible.

\subsection{Operational preconditions of waterworks systems function}

Basic technical-operational and functional preconditions of waterworks systems of water mains for the public need in the Czech Republic must meet two preconditions given below, depending on the type of water used for production or subsequently treated drinking water in distribution plants.

\section{Crude water meant for drinking water treatment}

In EU drinking water can be made only from the water meeting conditions for the category of treatment A1, A2, A3 [1].

For the need of the technological facility of the water treatment plants the operator can set approximate treatment index (Iu) at selected indicators, when regarding higher quality unsteadiness of crude water during the year, it is not possible to fit the source clearly into one category [1]:

$I_{u}=I_{u 1} \frac{a}{100}+I_{u 2} \frac{b}{100}+I_{u 3} \frac{c}{100}+I_{u 4} \frac{d}{100}$

\footnotetext{
* ${ }^{1}$ Sarka Krocova, ${ }^{2}$ Miloslav Rezac

${ }^{1}$ Faculty of Safety Engineering, VSB - Technical University of Ostrava, Ostrava - Vyskovice, Czech Republic

${ }^{2}$ Faculty of Civil Engineering, VSB - Technical University of Ostrava, Czech Republic

E-mail: miloslav.rezac@vsb.cz
} 
Where:

$a, b, c$ are frequency of presence of the indicator in category $\mathrm{A} 1, \mathrm{~A} 2, \mathrm{~A} 3$ in $\%$ and $d$ is frequency of presence of the indicator in category higher than $\mathrm{A} 3$.

The treatment index (Iu) is a figure in the range of 1 to 3 matching categories A1 to A3. Forhigher figures that are for category A3 is Iu4. An increasing treatment index is related toworsening quality of the source. The treatment index corresponds with the difficulty index which is given by figure from 0 to 3.75. The following approximate treatment index (Iu) matches roughly the standard method of water treatment according to demands on the water treatment technology.

The quality of crude waters demanded by the regulation from the year 2001 [1] will be extremely difficult to keep in the new climate conditions of the 21 st century. The average temperature, pollution of accumulated or running water and other negative effects will increase gradually, which will influence its treatment of drinking water.

\section{Drinking water}

Drinking water distributed by the waterworks systems of the water mains for the public use has very strict criteria which have to be kept during the whole process from its processing to the supply for the final consumer. The basic preconditions of the quality of drinking water and the qualities connected with drinking water are:

- Sanitation of drinking water while observing microbiological and physical-chemical index of water quality [1],

- water freshness in each profile of water distribution mains

- cerfications of all materials in contact with drinking water

- permanent monitoring of the drinking water quality in characteristic points of the distribution system.

The operational preconditions of the waterworks systems given above can be carried out in real operation only in coaction with hydraulic parameters by accumulation of drinking waters and specification of suitable dimension of water distribution mains.

\subsection{Hydraulic precondition of function of distribution mains of drinking water}

To guarantee the optimal working functions of all types water mains it is necessary to take into consideration surrounding in the pipe systems.

From the whole range of the matters dealing with the hydraulic of drinking water pipes and its output effect on the parameters relating consequently to the amount and quality of water it is inevitable to take into consideration the following terms and definitions.
Stationary flow is a flow the quantity of which does not change with time but only with location. The equation is:

$\mathrm{Q}=\mathrm{v} \cdot \mathrm{S}=$ const. $\quad\left[\mathrm{m}^{3} \cdot \mathrm{s}^{-1}\right]$

Nonstationary flow is a flow the quantity of which changes with the location and time.

stationary flow of a liquid ( $Q=$ const. $)$

even $\mathrm{S}_{1=} \mathrm{S}_{2}=$ const., $\mathrm{v}_{1}=\mathrm{v}_{2}=$ const.

uneven delayed $S_{1}<S_{3}, v_{1}>v_{3}$

accelerated $\mathrm{S}_{3}>\mathrm{S}_{4}, \mathrm{v}_{3}<\mathrm{v}_{4}$

A scheme of even and uneven liquid flows in pipes [2] is given in Fig. 1.

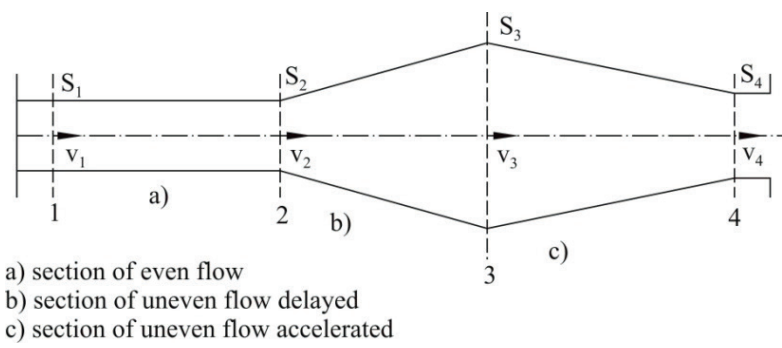

Fig. 1 Scheme of the liquid flow in pipes (adjusted by 2)

Water flow under the pressure

Resistence of the surrounding and the liquid is evident as: loss caused by friction $\mathrm{Zt}$,

loss by locality $\mathrm{Zm}$.

Total loss $\sum \mathrm{Z}=\sum \mathrm{Z}_{\mathrm{t}}+\sum \mathrm{Z}_{m}$

According to the type of designed pipes $\mathrm{Q}=\mathrm{v} \cdot \mathrm{S}=$ const., the rate should move within the following limits:

$\mathrm{d}=\sqrt{\frac{4 \mathrm{Q}}{\pi \mathrm{V}}}$

$v=\sqrt{\frac{2 \mathrm{gH}_{0}}{1+\lambda \frac{1}{\mathrm{~d}}}}$

$\mathrm{d}$ - searched average $[\mathrm{m}]$,

$\mathrm{Q}$ - flow rate $\left[\mathrm{m}^{3} / \mathrm{s}\right]$,

$\mathrm{v}$ - proposal speed of water in the pipeline $[\mathrm{m} / \mathrm{s}]$.

$\mathrm{H}_{\mathrm{O}}=\frac{\mathrm{V}_{1}^{2}}{2 \mathrm{~g}}+\sum \mathrm{Z}$

According to the type of designed pipes, the rate should move within the following limits: 
suction line

$0.4-0.6 \mathrm{~m} . \mathrm{s}^{-1}$,

discharge line

$0.6-1.2 \mathrm{~m} . \mathrm{s}^{-1}$,

gravitation line

$1.0-1.5 \mathrm{~m} . \mathrm{s}^{-1}$.

The rate of water flow is always a key factor in the maintenance of drinking water quality, its freshness, and simultaneously the adherence to the stated values prevents the cavitation regime.

\subsection{Methods of water supply system calculation}

For the successful mathematical modelling of local water supply systems of towns and municipalities and simultaneously also inside water supply systems of industrial parks, the following conditions must be fulfilled [3 and 4]:

a) Node condition: The sum of inflows, outflows and quantities demanded at each node of the water supply system must be zero.

$\sum_{i=1}^{m}\left(a_{i j} Q_{i}\right)+G_{j}=0$

$\mathbf{Q}_{\mathrm{i}}$ - rate of flow in section i $\left[\mathrm{m}^{3} \cdot \mathrm{s}^{-1}\right]$,

$\mathbf{a}_{\mathrm{ij}}$ - expresses whether node $\mathrm{j}$ is the initial or final node of section $\mathrm{i}$,

$\mathbf{G}_{\mathrm{j}}$ - quantity demanded from node $\mathrm{j}\left[\mathrm{m}^{3} \cdot \mathrm{s}^{-1}\right]$.

b) Loop condition: In each loop of the water supply system, pressures will be equalized. If we give the sign, which is identical with that of the direction of flow at the same basic orientation of the positive flow in the loop, to the head losses in the section, the sum of the head losses in the loop will be zero.

$\sum_{i=1}^{m}\left(b_{i k} h_{i}\right)=0$

$\mathbf{h}_{\mathbf{i}}$ - head loss in section i [m],

$\mathbf{b}_{\mathrm{ik}}$ - expresses whether the given section $\mathrm{i}$ is part of loop $\mathrm{k}$.

c) Hydraulic condition: It describes a relation between head loss and flow rate in the section.

$h_{i}=k_{i} Q_{i}^{2}$

$\mathrm{h}_{\mathrm{i}}-$ head loss in section $\mathrm{i}(\mathrm{m})$

$k_{i}=\frac{8}{g \pi^{2}} \lambda_{i} \frac{l_{i}}{d_{i}^{5}}$

1 - friction factor,

$\mathrm{d}_{\mathrm{i}}$ - internal pipe diameter in section $\mathrm{i}[\mathrm{m}]$. d) For the calculation of a looped system, which consists of $m$ sections and $\mathrm{n}$ nodes, we shall get s loops:

$\mathrm{s}=\mathrm{m}-\mathrm{n}+1$

Source path condition: The loss in the source path equals to the difference between height levels, free discharges, etc. of end nodes of the source path. If the number of pressure-dependent nodes is $y$, the number of source paths is equal to $y-1$.

$\sum_{i=1}^{m}\left(c_{i y} h_{i}\right)=H_{y}^{P}-H_{y}^{K}$

hi - head loss in section i [mm],

ciy - orientation of sections of the source path,

HyP,K- level of pressure head at nodes at the beginning and at the end of the source path.

Detailed knowledge of operating and hydraulic parameters of the water supply system being dealt with substantially increases the efficiency of safety planning and improves preventive preparation for coping with potential extraordinary events.

\section{Safety risks of the functional changes of waterworks systems}

It is not possible to prevent the cases of emergency in the water-supply engineering. It is possible to prepare on their progress and negative impact in advance from operational-safety analysis. The changes in functioning of the waterworks facilities are always caused by two causes with different potential of negative impact on the supplies of drinking water to consumers.

\subsection{Natural influence}

Natural influence is tightly connected with water ecosystems and also with the resources of surface and subterranean waters. Negative impact on the waterworks systems functioning can be caused by:

- the change of climatic conditions (long-term droughts, water temperature and floods),

- natural higher releasing of inorganic rocksubstances into water,

- earthquake and following breaks of the land relief including the disturbing of aquiferous levels,

- landslides disturbing linear constructions of the waterworks systems.

Natural operational-safety risks can be predicted by the means of risk analysis and reasonably the lowest negative impact can be prepared. 


\subsection{Anthropogenic contingencies}

Anthropogenic contingencies have their occurrence in human activities. They show negatively on the water resources especially on distribution systems. They are mainly caused by the following characteristic features:

- breaking the regulations for activities and water management in water resourcesprotection zones, leakage of contamination substance from old ecological burdens into subterranean waters,

- breaking the regulations for economical use of drinking water by the operators of waterworks systems and subsequent secondary contamination of drinking water in accumulations or piping.

- leakage of dangerous substances from industrial activities or traffic accidents into surface waters,

- unintentional damage of waterworks linear construction during earthwork,

- international damage or terrorism.

Most of anthropogenic contingencies can be hardly predicted. In most cases they occur due to the lack of technological discipline and by breaking obligatory regulations.

\section{Discussion}

Considering that operability of waterworks systems including water resources and continuity in water supplying is everybody's concern, it is important not only to run education but firstly to lead discussion among experts and look for ways how to make the present state better.

Professional discussion should be focused, for example, on the following fields:
- looking for new economically feasible ways improving the balance of water reserves in the climatic conditions of the Czech Republic.

- lowering the secondary risk of drinking water contamination during operation breakdown and finding methods how to prevent deliveries of contaminated water to consumers [5].

- considerable increasing of hydraulic efficiency of water mains.

Discussion on this and other issues in the field of water management can considerably advance and make more effective not only the waterworks but, in the wider context, also water management especially in the conditions of the forthcoming changes in the mild climatic zone.

\section{Conclusion}

This article in its basic range shows the ways and means for increasing the reliability of drinking water deliveries for built-up areas of the cities and villages to which the discussion and attention are focused with the aim to increase efficiency of operational waterworks systems. Regarding the forthcoming minimally regional shortage of water the present change of the approach to the water management can be considered absolutely necessary.

\section{Acknowledgement}

This contribution was prepared as a part of the grant project of the Ministry of the Interior of the Czech Republic under number VF20112015018, titled Safety of Citizens - Crisis Management (in Czech).

\section{References:}

[1] Decree of Ministry of Health No. 428/2001 Coll., implementing Act No. 274/2001 Coll., on Water Supply and Sewerage Systems for Public Use. Collection of Laws 2004, section 48, 2004.

[2] SLOVACKOVA, M., SULC, M.: Technical Handbook for Water Managers - Secondary Building School (in Czech), Lipnik nad Becvou, 1998.

[3] INGEDULT, P., VYCITAL, J.: Mathematical Modelling of Water Supply Networks - Part 1 (in Czech), Sovak, vol. 8, No. 3, 1999.

[4] ODULA: Program Agent Manual (in Czech), DHI Hydroinform a. s., 2001.

[5] BERNATIK, A., SENOVSKY, P., SENOVSKY, M., REHAK, D.: Territorial Risk Analysis and Mapping. Chemical Engineering Transactions, 31, 79-84, 2013. 